\title{
Caracterização das atividades informais - o comércio de rua de goiânia
}

\author{
Carlos LeÃo* \\ A line Tereza Borghi Leite**
}

\begin{abstract}
R esumo: O estudb busca analisar as causas de inserção de trabalhadbres no comércio de nua do Centro de Goiânia. Para isso, utiliza uma amostra de 203 questionários aplicados entre os camelôs que aturm nas áreas centrais da cidade. Recorreurse à técnica estatística de análise fatorial, por meio de uma análise de componentes principais, com processamento realizado pelo programa SPSS. Os resultados da análise fatorial parecem indicar que os fatores que explicam o fenômeno estão relacionados à migração de trabalhadores desempregados do interior para Goiânia, ao tempo de permanência do camelô na atividade, à proteção de que o camelô dispõe no que se refere aos direitos trabalhistas, entre outros. Constata-se que o desemprego levou os trabalhadores a exercerem atividades informais no Centro de Goiânia.
\end{abstract}

Palavras-chave: desemprego; análise fatorial; trabalho informal.

1. Introdução

Singer (2003) afirma que, atualmente, estamos atravessando uma Terceira R evolução Industrial, que provoca um aumento de produtividade mediante desemprego tecnológico, combinado com o desaparecimento de postos de trabalho.

A ssim, o resultado da Terceira R evolução Industrial no mundo do trabalho é que muitas atividades desconectam-se do grande capital monopolista e começam a ser exercidas por pequenos empresários, trabal hadores autônomos, transformando empregos formais em ocupações que não garantem direitos aos trabalhadores (Singer, 2003).

Esse autor reconhece que a globalização causa o "desemprego estrutural", cujos ef eitos são muito semelhantes aos do desemprego

\footnotetext{
* Doutor em Economia A plicada pela UFV-M G; professor de M étodos Quantitativos A plicados a Ciências Sociais UFG

** M estranda em Sociologia pela UFG.
}

tecnológico, pois "ele não aumenta necessariamente o número total de pessoas sem trabal ho, mas contribui para deteriorar o mercado de trabal ho para quem precisa vender sua capacidade de produzir" (Singer, 2003, p. 23,). Isto é, a globalização propicia a eliminação de postos de trabalho.

Singer (2003) acredita que a palavra "precarização do trabalho" - que se refere à crescente destruição dos direitos sociais e trabal histas - descreve melhor a presente situação do que a palavra "desemprego". Os novos postos de trabalho, que vêm surgindo em virtude das transformações das tecnologias e da divisão internacional do trabal ho, não oferecem ao trabaIhador as compensações que as leis e contratos coletivos garantiam.

N esse contexto, para a efetiva flexibilidade do aparato produtivo, é necessária uma flexibilização da organização do trabal ho (A ntunes, 1995). Com isso, o mercado exige um comportamento cada vez mais flexível de seus atores. 
A ssim, ao procurar compreender o desemprego em contextos de intensa flexibilização do trabalho, verifica-se uma al teração nas relações sociais de trabal ho, caracterizada pela retração das formas de contratação integral e de um avanço nas formas "atípicas" de emprego, além de um aumento no trabalho por conta própria.

Com a precarização do trabalho, os trabaIhadores, que eram assalariados e trabal havam em tempo integral, passaram a ser engajados como autônomos, avulsos, trabalhadores em tempo parcial ou por tempo limitado ou sua ocupação foi eliminada pelos progressos da informática (Singer, 2003).

Em tais condições, os ocupados por conta própria precisam trabalhar cada vez mais para ganhar o suficiente para manter o seu padrão usual de vida, na medida em que seus ganhos se baseiam no montante de serviços prestados e não mais no tempo de trabal ho.

Entretanto, 0 aumento do tempo de trabal ho dos ocupados reduz a possibilidade de os semtrabal ho conseguirem uma ocupação. Com isso, Singer (2003) conclui que enquanto uma parte dos trabalhadores trabal ha mais por uma remuneração horária declinante, outra parte crescente dos trabalhadores deixa de poder trabalhar.

Esses indivíduos saem da condição de desempregados por meio da aquisição de um novo emprego, descobrindo novas al ternativas de ocupação, que não se trata de uma ocupação estável, um posto de trabalho de boa qualidade, pois eles não oferecem condições de empregabilidade (Guimarães, 2002).

Essa idéia de "empregabilidade" sustenta que o nível de capital humano diferencia os trabalhadores, fazendo com que as chances de sobrevivência em contextos reestruturados aumentem conforme a qualificação individual (Guimarães, 2002).

Nesse contexto, as condições de "empregabilidade" referem-se à capacidade humana de gerir o próprio destino e prover meios para a sua sobrevivência. É como se a probabilidade de obtenção do emprego dependesse da capacidade individual do trabalhador.

No entanto, é importante ressaltar que a (re)inserção no mercado de trabal ho não depende somente da vontade e da conduta dos traba-
Ihadores, mas também de fatores estruturais externos que não estão ao alcance deles, na medida em que fazem parte das estratégias das empresas na ampliação dos seus ganhos.

Singer (2003) sustenta que a crescente "informalização" se refere a uma tendência mundial e é resultado do processo de abertura das economias nacionais à competição internacional e das mudanças que a informatização trouxe para o mundo do trabal ho. Com isso, o emprego formal no B rasil começou a diminuir, enquanto o emprego informal e o trabalho autônomo aceleraram o ritmo de seu crescimento.

No universo do setor informal, o enfoque dado por esta pesquisa é acerca da comercialização de rua. A economia de rua seria a expressão externa da economia informal (Y ázigi, 2000).

Nessa esfera, a principal questão que se apresenta para esta pesquisa é entender quais são as causas da inserção de trabalhadores no comércio de rua do Centro de Goiânia. Pretendese, desse modo, testar a hipótese de existência de determinados fatores causais da inserção na informal idade. U ma das hipóteses desta investigação é que os trabalhadores se inserem na atividadeinformal do Centro de Goiânia em razão do desemprego.

A escolha pelo trabal ho autônomo também pode se dar com o intuito de obter liberdade de empreendimento, para fugir do "relógio de ponto" e, com isso, não se submeter a um patrão. Vale mencionar que essa questão foi considerada um dos fatores explicativos do ingresso no comércio informal do Centro de Goiânia, presentes nos questionários aplicados.

Y ázigi (2000) lembra que esse motivo de inserção no mercado informal contraria a afirmação de que esse setor abarca os desempregados que não conseguiram vaga no mercado formal de trabalho. Trata-se de uma opção, na medida em que o camelô pode se demitir voluntariamente em busca de ascensão via mercado informal. Isto significa que uma determinante da atividade informal seria a vontade própria dos trabal hadores de poderem trabal har com horário livre.

Singer (2003) acredita que é fundamental fazer uma distinção entre os empregados 
informais que trabal ham voluntariamente (ou seja, ao serem perguntados se gostariam de retornar ao mercado formal, eles respondem que não, seja por terem a possibilidade de fazer seus próprios horários, seja pelo fato de não precisarem se submeter a um patrão ou ainda para complementação da renda) e os que só se inserem no mercado informal por serem incapazes de encontrar um emprego formal, isto é, estão excluídos do emprego formal contra sua própria vontade, e se constituem como excedente da oferta de mão-de-obra do mercado formal de trabalho.

Nesse sentido, esta pesquisa também procura saber se os camelôs que exercem suas atividades informais no Centro da capital goianiense gostariam de retornar ao mercado formal de trabal ho.

Noronha (2002) afirma que, no Brasil, o entendimento popular de "trabalho formal" ou "informal" deriva da ordem jurídica. São informais os empregados que não têm carteira de trabal ho assinada. Esse autor sustenta que a carteira de trabal ho tem significados simbólicos e que funciona como uma verdadeira carteira de identidade ou como comprovante para a garantia de crédito ao consumidor, o que mostra que o trabal hador é confiável e pode comprovar um vínculo empregatício. Dessa forma, esta pesquisa procura saber se o camelô de Goiânia tem registro atual na sua carteira de trabalho.

Para Singer (2003), a fal ta de bons empregos é universal, um fenômeno que existe praticamente em todos os países desenvolvidos e semidesenvolvidos. A o fal ar de universal idade do desemprego, é interessante lembrar a idéia de Horta (2001), que chama a atenção para a questão da banalização do desemprego, ao afirmar que este é visto com muita naturalidade, o que fortalece as condições de sua permanência e do conformismo em relação à perda da qualidade de vida, da dignidade e da cidadania dos trabalhadores. Isso reforçaria uma cultura de tolerância em torno da injustiça social, uma vez que o desemprego institucionalizado é sustentado pelas teses neoliberais de mercado livre e flexibilização do trabalho.

Dentro dessa concepção, o conformismo da sociedade e a acei tação de explicações como "o desemprego existe no mundo inteiro" alimen- tam a lógica da destruição de postos de trabalho e da precarização dos direitos dos trabal hadores. Trata-se da consolidação de uma "Iegitimidade" para o desemprego (Horta, 2001).

Segundo Singer (2003), nós necessitamos é de "ocupação", que não é sinônimo de "emprego" - "ocupação" compreende toda atividade que propicia sustento a quem a exerce, enquanto "emprego" implica assalariamento, uma vez que uma relação de emprego só existe quando alguém dá um emprego a alguém. Para esse autor, o problema da ocupação não deve ser reduzido ao do emprego, já que emprego assalariado é um tipo de ocupação, mas não o único.

A ssim, acredita-se que a única maneira de al guém se sustentar é vendendo sua capacidade de produção ao capital, visão que desconsidera as várias formas de atividade autônoma que vêm crescendo à medida que o capital diminui o volume de força de trabalho que emprega (Singer, 2003).

Horta (2001) também comenta essa questão, dizendo que o crescimento do mercado informal é resultado da diminuição dos postos de trabalho. Segundo ele,

as mudanças verificadas no processo produtivo e na reestruturação das empresas, em um contexto de recessão econômica, têm provocado forte precarização do trabal ho. A o mesmo tempo, viabilizaram propostas de desregulamentação e de flexibilização, abrindo espaço para a defesa da privatização e seus efeitos nocivos, como o crescimento explosivo do mercado informal, como conseqüência imperativa da diminuiçãa dos espaços de trabal ho. (H orta, 2001, p. 14)

Horta (2001) sustenta que, com a transferência de trabalhadores para o setor informal, verifica-se uma diminuição do exercício da cidadania do trabalhador. Com isso, "ao tentar se estabelecer na economia informal, o desempregado perde substancial mente na sua cidadania e na sua dignidade, pois aqui são maiores as dificuldades para que ele se constitua como sujeito coletivo, através, por exemplo, de uma vida sindical organizada" (H orta, 2001, p. 15).

Esta pesquisa busca, portanto, caracterizar as atividades informais do Centro de G oiânia e, com base nos dados obtidos, conhecer quem são 
os camelôs que atuam no comércio de rua dessa região. A relevância deste estudo reside na preocupação de entender como as transformações na esfera do trabal ho atingem a vida dos trabalhadores que atuam nas atividades informais goianienses.

\section{M aterial e método}

\subsection{F onte de dados}

Os dados sobre os indicadores da ocorrência do trabal ho informal no Centro de Goiânia (nas Avenidas A nhangüera e Goiás) foram coletados a partir da aplicação de 203 questionários entre os 1065 vendedores ambulantes registrados na Secretaria de Desenvolvimento M unicipal (Sedem) no ano de 2003. 0 questionário foi a técnica sistemática de coleta de informações utilizada, no intuito de identificar as variáveis que caracterizam as atividades informais do Centro de G oiânia.

\subsection{M etodologia}

A nálise fatorial

A análise fatorial é uma técnica multivariada que serve para reduzir a complexidade de variáveis a uma maior simplicidade (K erlinger, 1980). Sendo assim, a

análise fatorial constitui uma técnica de extrema importância quando se trata de representar um grande número de variáveis por um número reduzido, a partir da formação de agrupamentos das variáveis originais que apresentam alta correl ação entre si. (Souza e K han, 2001, p. 80)

A análise fatorial foi empregada neste estudo a fim de obter os fatores envolvidos no processo de decisão de inserção no comércio informal goianiense. Por meio dessa técnica, pretende-se testar a hipótese de existência de alguns fatores causais que determinam, entre as variáveis observadas, o motivo de ingresso na informalidade. Portanto, a "análise fatorial é essencialmente um método para determinar 0 número de fatores existentes em um conjunto de dados, para determinar quais testes ou variáveis pertencem a quais fatores e em que extensão os testes ou variáveis 'pertencem a' ou estão 'saturados com' o que quer que seja 0 fator" (K erlinger, p. 214, 1980).

Um fator geral é uma variável hipotética, não-observável, que contribui para a variância de duas variáveis observadas, enquanto um fator único é uma variável hipotética enão observável que contribui para a variância de uma única variável observada. Dessa forma, o model o para uma análise de fatores geral contém um único fator para cada variável observada, 0 que pode ser visto na seguinte equação:

$$
\begin{aligned}
& \text { yij =xi1 blj }+x i 2 b 2 j+\ldots+x i q b q j+e i j, \\
& \text { Sendo que: }
\end{aligned}
$$

yij é o valor da i-ésima observação na j-ésima variável.

xik é o valor da i-ésima observação no k-ésimo fator geral

bkj é o coeficiente de regressão do k-ésimo fator geral para a estimação da j-ésima variável. eij é o valor da j-ésima observação no j-ésimo fator único.

q é o número do fator geral.

É assumido, por conveniência, que todas as variáveis têm média zero. Com isso, em termos matriciais, essa equação se reduz para:

$$
Y=X B+E
$$

Em que $X$ é a matriz de escores do fator e $B$ é o padrão do fator.

A análise fatorial foi elaborada em quatro etapas. A primeira buscou determinar a matriz de correlações entre todas as variáveis, verificando o grau de associação entre elas. N essa etapa, as variáveis pouco relacionadas com as demais tendem a apresentar baixa proporção de variância explicada pelos fatores comuns e devem ser eliminadas da análise (M eyer e B raga, 2001).

A segunda etapa refere-se à extração dos fatores mais significativos para representar os dados. 0 método de cálculo para a obtenção dos fatores foi o dos "componentes principais".

A terceira etapa remete à rotação dos "componentes principais" e objetiva encontrar uma estrutura simples de associação entre os fatores e as variáveis. N este estudo, foi utilizado 
um método de rotação ortogonal (Varimax), que tenciona minimizar o número de variáveis fortemente relacionadas com cada fator, propiciando a obtenção de fatores mais facilmente interpretáveis. Já a quarta etapa limita-se à geração dos escores fatoriais, que são os coeficientes de correlação.

$\mathrm{N}$ a análise fatorial, cada fator é constituído por uma combinação linear das variáveis originais incluídas na pesquisa. A associação entre fatores e variáveis dá-se por meio das cargas fatoriais, que podem ser positivas ou negativas (Souza e K han, 2001).

Segundo Kerlinger (1980), a maioria das variáveis participa de uma idéia central, al gum núcleo de significado que permite identificar o fator. Com isso, o fator pode ser definido por meio das correlações com as variáveis.

A Correlação Linear Simples foi utilizada para operacionalizar a pesquisa, pois verifica a existência e o grau da relação existente entre variáveis aleatórias, examinando se 0 grau de correlação entre variáveis é fraco, forte e nulo. A ssim, o coeficiente de correlação foi adotado como instrumento analítico para indicar o grau de intensidade da correlação entre duas variáveis, e estudar o sentido dessa correlação, isto é, se ele é positivo ou negativo.

0 coeficiente de correlação pode variar entre -1 e +1 , o que significa que se a correl ação entre duas variáveis for perfeita e positiva, então o coeficiente é +1 ; se a correlação for perfeita e negativa, então o coeficiente é - 1 . Por outro lado, se não houver correlação entre as variáveis, então o coeficiente é igual a 0.

Kerlinger (1980) afirma que, no âmbito da análise fatorial, tanto as cargas altas quanto as baixas são importantes na interpretação. Esta pesquisa também considera o coeficiente de correlação forte e negativo, pois este exerce efeito contrário sobre o fator.

Em suma, a análise fatorial é empregada como referencial empírico nesta pesquisa para agrupar as variáveis que têm um alto coeficiente de correlação, a fim de determinar as relações entre as diversas variâncias compartilhadas (K erlinger, 1980).

\subsection{Definição das variáveis}

As variáveis construídas - com base nas respostas dos questionários - para determinar os fatores que explicam o fenômeno em questão são:

O rdem: identificação do pesquisado

I dade: idade dos pesquisado

$N$ atural: origem do entrevistado

B airro: o bairro em que reside 0 camelô

Sexo: o sexo do camelô pesquisado

Endereço: o tempo de residência no endereço atual

Goiânia: o tempo de residência em Goiânia

M igrou: o que levou o pesquisado a migrar do interior

Terras: se, no interior, o camelô possuía terras

Possui: se o camelô ainda possui terras no interior

Venda: o motivo de venda da terra

E mprego: o último emprego no interior

Civil: o estado civil do pesquisado

Filhos: seu número de filhos

Família: o número de pessoas na família

Trabalha: o número de pessoas que trabal ha na família

Informal: o número de pessoas na família que trabal ha no mercado informal

Escola: a escolaridade do entrevistado

Inserir: o que levou o trabal hador a se inserir na atividade informal de Goiânia

A nterior: seu emprego anterior em G oiânia

Ú nica: se a atividade informal éa principal fonte de renda da família

Tempo: o tempo de atividade no mercado informal

Situação: se o pesquisado é permissionário ou dono da banca

Procura: a última vez que o camelô procurou emprego formal

M oradia: o tipo de sua residência

Renda: a renda nesta profissão

Outras: se o camelô possui outras rendas

INSS: se o camelô contribui com o INSS 
CTPS: se o camelô tem registro atual na sua carteira de trabalho

Formal: se o camelô gostaria de retornar ao mercado formal

\section{R esultados e discussão}

\subsection{D escrição dos dados}

Com base nos dados tabulados, é possível traçar um perfil dos camelôs que exercem suas atividades no Centro de Goiânia. Isto é, as variáveis fornecidas pelo questionário nos dão al gumas informações que permitem a caracterização das atividades informais dessa região.

No que se refere às faixas etárias, $2,5 \%$ dos camelôs pesquisados situam-se entre 15 e 18 anos; $27,5 \%$, entre 19 e 25 anos; $15,8 \%$, entre 26 e 30 anos; $33 \%$, entre 31 e 40 anos; $12,8 \%$, entre 42 e 50 anos, e $8,4 \%$, entre 51 e 66 anos. É interessante observar que $54,2 \%$ dos camelôs têm mais de 30 anos.

Sobre o sexo, revelam-se percentuais de $56,7 \%$ de homens e $43,3 \%$ de mulheres, sendo $36,5 \%$ solteiros; $57,1 \%$ casados; $2 \%$ desquitados; $2,5 \%$ divorciados; 0,5 viúvos e $1,5 \%$ em outros estados.

Sobre a escolaridade, nota-se uma preponderância de pessoas com $01^{\circ}$ grau incompleto $(29,1 \%)$; de $20,2 \%$ de pessoas com o $1^{\circ}$ grau completo; de $14,3 \%$ com ensino elementar; $17,7 \%$ com o $2^{\circ}$ grau ou técnico completo; de $13,8 \%$ com o $2^{\circ}$ grau ou técnico incompleto. A penas $1 \%$ da amostra têm $3^{\circ}$ grau completo e $3,9 \%$ deles têm $3^{\circ}$ grau incompleto.

0 número de filhos é apontado como: nenhum (31,5\%); um (22,7\%); dois (26,1\%); três $(13,3 \%)$; quatro $(4,4 \%)$; cinco $(1 \%)$; seis $(0,5 \%)$ e treze filhos $(0,5 \%)$.

Com isso, 35\% dos entrevistados tem até 3 pessoas na família; $49,8 \%$, de 3 a 5 e 15,3\% dos camelôs tem mais de 5 pessoas na família. 0 número de pessoas que trabal ham na família é definido como: uma pessoa $(19,7 \%)$; duas $(50,2 \%)$; três $(13,8 \%)$; quatro $(10,8 \%)$; cinco $(4,4 \%)$; seis $(0,5 \%)$ e oito pessoas $(0,5 \%)$. Destes, $71,9 \%$ têm uma pessoa na família que trabalha no mercado informal; $24,6 \%$ têm duas pessoas; $2 \%$, três pessoas; $0,5 \%$, quatro pessoas, e $1 \%$, cinco pessoas.
0 bairro em que $93,1 \%$ dos pesquisados residem encontra-se em Goiânia, enquanto 6,9\% dos pesquisados situam-se na Região $M$ etropol itana de Goiânia. Sabe-se também que $16,7 \%$ dos pesquisados residem no endereço atual há 1 a 2 anos; 17,2\%, há 3 a 5 anos e $66 \%$ residem no mesmo endereço há mais de 5 anos. Além disso, $6,4 \%$ dos camelôs moram em Goiânia há 1 a 2 anos; $10,3 \%$, há 3 a 5 anos e $83,3 \%$ residem há mais de 5 anos na capital goianiense.

Desses camelôs, 43,8\% moram em casa própria; $29,6 \%$, em casa alugada; $4,9 \%$, em casa cedida; $1,5 \%$, em apartamento próprio; 3,4\%, em apartamento alugado; 7,9\%, em barracão próprio, e 1\%, em barracão cedido.

Quanto à origem, $29,6 \%$ são naturais de Goiânia; $26,1 \%$, do interior de Goiás e 44,3\% são de outros estados. N esta amostra, dos camelôs que migraram do interior, 33,57\% mudaram-se em razão do desemprego; 7,14\%, por opção; 6,43\%, para estudar, e 52,86\%, por outros motivos.

A pesar de cerca de $70 \%$ dos camelôs pesquisados serem migrantes, pode-se afirmar que a migração da força de trabal ho do pequeno proprietário de terras do campo à cidade não pode ser considerada uma determinante do crescimento do setor informal nas áreas centrais goianienses, uma vez que apenas $9,9 \%$ dos camelôs instalados no Centro de Goiânia possuíam terras no interior; $58,1 \%$ não as possuíam, e 32\% não provêm do interior.

Sendo assim, $1 \%$ dos camelôs ainda possuem terras no interior, $60,6 \%$ não possuem e $38,4 \%$ nunca possuíram. Para $5,9 \%$, a necessidade de dinheiro representou o motivo para venda da terra, 3\% apresentaram outros motivos e $91,1 \%$ dos camelôs nunca possuíram terras para vender.

A variável "inserir" permite-nos testar a hipótese levantada no início desta pesquisa, pois, nesse universo de 203 pesquisados, 71,4\% declararam que o desemprego foi a causa de sua inserção no mercado informal de trabalho; $15,3 \%$ ingressaram na informalidade para complementar a renda; 8,4\% para não terem patrão e $4 \%$ se inseriram por outros motivos.

Com isso, independentemente de o camelô ser migrante ou proveniente de Goiânia, 0 desemprego foi a principal causa de seu ingresso 
no comércio de rua da cidade, pois, dos camelôs que vieram do interior, $57,78 \%$ estavam desempregados no interior; $14,7 \%$ trabal havam na agricultura e $28,15 \%$, em outras atividades.

Contudo, essa informação parece indicar que $a$ atividade informal também pode se referir a uma opção de vida de alguns trabalhadores que preferem construir o seu "próprio negócio" e, assim, não ter de se subordinar a um patrão ou ainda para complementar a renda familiar.

$\mathrm{N}$ o que se refere ao emprego anterior em Goiânia, 5,9\% dos camel ôs são provenientes da indústria; $13,3 \%$ do comércio; $34,5 \%$ do setor de serviços; $15,8 \%$ eram autônomos e 30,5\% vieram de outros empregos.

A renda mensal declarada nessa profissão é de até 1 salário mínimo (18,2\%); de 1 a 2 salários (56,7\%); de 2 a 3 salários (10,8\%); de 3 a $5(11,3 \%)$; de 5 a $10(2 \%)$ e acima de 10 salários (1\%). N esta amostra, 82,3\% têm banca própria; $14,3 \%$ são permissionários e 3,4\% se enquadram em outra situação.

A respeito da última vez que essas pessoas procuraram emprego formal, $82,3 \%$ declararam que foi há mais de 6 meses, enquanto somente $1 \%$ dos camelôs procuraram emprego há até 1 mês; $3 \%$ de 2 a 4 meses e $13,8 \%$ de 4 a 6 meses.

Este dado nos permite inferir que esses camelôs assumiram sua condição na informalidade, na medida em que a atividade informal é uma ocupação que Ihes garante o sustento, pois, para $70 \%$ dos pesquisados, a atividade informal é a principal fonte de renda da família. Com isso, dos trabal hadores informais pesquisados, $59,6 \%$ não desejam retornar ao mercado formal de trabalho.

A lém disso, o tempo de permanência como camelô revela que $30,5 \%$ estão nesta atividade há até 2 anos; $10,3 \%$ entre 2 e 3 anos; 18,7\% entre 3 e 4 anos, e 40,4\% estão há mais de 5 anos na informalidade.

N esse universo, $97,5 \%$ não contribuem com o IN SS e 98\% não têm registro atual na CTPS. Esses trabalhadores, ao ingressarem na informalidade, ficam excluídos da possibilidade de usufruírem direitos trabalhistas que são garantidos aos trabal hadores formais que contribuem com o pagamento de impostos e tributos.

\subsection{Interpretação dos dados}

A pós serem selecionadas as variáveis, determina-se a matriz de correlações simples, 0 que vai levar à extração dos fatores, pelo "método dos componentes principais".

0 critério utilizado para determinar o número de fatores foi selecionar aqueles que apresentam raiz característica (eigen values) maior que a unidade.

$\mathrm{Na}$ Tabela 1, onze componentes principais apresentam raiz característica maior que a unidade e "explicam" cerca de $67 \%$ da variância total 0 primeiro fator tem maior peso explicativo (explica cerca de $16 \%$ da variância dos indicadores) do que o segundo fator, que consegue explicar cerca de $9 \%$ da variância, e que é mais explicativo do que o terceiro fator, que explica cerca de $6 \%$, e assim por diante.

É importante ressaltar que a comunalidade "informa a proporção da variância total de cada variável que é explicada pelo conjunto de fatores considerados na análise, ao passo que a soma do quadrado dos coeficientes de saturação para cada fator denomina-se eigen value" (Souza e $K$ han, 2001, p. 80). Isto é, o valor da comunalidade é obtido por meio do somatório do quadrado das cargas fatoriais de cada variável. A tabela de comunalidade pode ser vista na Tabela 2.

U ma vez utilizado o "método dos componentes principais", seguido da rotação ortogonal dos eixos (Varimax), as cargas fatoriais vão corresponder a coeficientes de correlação entre o fator e a variável.

Desse modo, os valores são entendidos como cargas fatoriais, "índices que mostram o grau de relação [...] são as correlações entre cada variável e o fator" (K erlinger, 1980, p. 213). As relações entre cada variável original e os novos fatores são medidas pelas cargas fatoriais.

A s cargas iguais ou maiores que 0,60 foram consideradas suficientemente grandes para merecerem interpretações. D eve-se lembrar que as cargas fatoriais obtidas são reduções de dados muito mais complexos a tamanhos manuseáveis para que se possa interpretar melhor os resultados (K erlinger, 1980).

Deve-se ressal tar que a carga fatorial é um coeficiente que expressa o quanto uma variável 
LEÃO, C.; LEITE, A. T. B. Caracterização das atividades informais...

Tabela 1 - Fatores extraídos pelo método dos componentes principais - Variância Total Explicada

\begin{tabular}{|c|c|c|c|c|c|c|c|c|c|}
\hline \multirow[b]{2}{*}{ Componente } & \multicolumn{3}{|c|}{ Raiz Característica } & \multicolumn{3}{|c|}{$\begin{array}{l}\text { Extração da soma } \\
\text { das cargas iguais }\end{array}$} & \multicolumn{3}{|c|}{$\begin{array}{l}\text { Rotação da soma } \\
\text { das cargas iguais }\end{array}$} \\
\hline & Total & $\begin{array}{c}\text { Variância } \\
\text { Explicada } \\
(\%)\end{array}$ & $\begin{array}{l}\text { Variância } \\
\text { Acumulada } \\
\quad(\%)\end{array}$ & Total & $\begin{array}{c}\text { Variância } \\
\text { Explicada } \\
\text { (\%) }\end{array}$ & $\begin{array}{l}\text { Variância } \\
\text { Acumulada } \\
(\%)\end{array}$ & Total & $\begin{array}{c}\text { Variância } \\
\text { Explicada } \\
\quad(\%)\end{array}$ & $\begin{array}{c}\text { Variância } \\
\text { Acumulada } \\
\text { (\%) }\end{array}$ \\
\hline 1 & 4,801 & 16,003 & 16,003 & 4,801 & 16,003 & 16,003 & 4,304 & 14,348 & 14,348 \\
\hline 2 & 2,794 & 9,313 & 25,316 & 2,794 & 9,313 & 25,316 & 2,142 & 7,141 & 21,489 \\
\hline 3 & 2,037 & 6,789 & 32,106 & 2,037 & 6,789 & 32,106 & 1,979 & 6,596 & 28,085 \\
\hline 4 & 1,733 & 5,775 & 37,881 & 1,733 & 5,775 & 37,881 & 1,935 & 6,450 & 34,535 \\
\hline 5 & 1,621 & 5,405 & 43,286 & 1,621 & 5,405 & 43,286 & 1,764 & 5,879 & 40,414 \\
\hline 6 & 1,471 & 4,903 & 48,188 & 1,471 & 4,903 & 48,188 & 1,643 & 5,478 & 45,892 \\
\hline 7 & 1,306 & 4,352 & 52,540 & 1,306 & 4,352 & 52,540 & 1,352 & 4,506 & 50,398 \\
\hline 8 & 1,246 & 4,153 & 56,693 & 1,246 & 4,153 & 56,693 & 1,337 & 4,457 & 54,855 \\
\hline 9 & 1,147 & 3,825 & 60,518 & 1,147 & 3,825 & 60,518 & 1,315 & 4,384 & 59,239 \\
\hline 10 & 1,118 & 3,727 & 64,245 & 1,118 & 3,727 & 64,245 & 1,292 & 4,307 & 63,545 \\
\hline 11 & 1,074 & 3,579 & 67,824 & 1,074 & 3,579 & 67,824 & 1,284 & 4,279 & 67,824 \\
\hline 12 & 0,980 & 3,265 & 71,090 & & & & & & \\
\hline 13 & 0,881 & 2,936 & 74,025 & & & & & & \\
\hline 14 & 0,816 & 2,719 & 76,744 & & & & & & \\
\hline 15 & 0,778 & 2,594 & 79,338 & & & & & & \\
\hline 16 & 0,699 & 2,330 & 81,668 & & & & & & \\
\hline 17 & 0,646 & 2,152 & 83,820 & & & & & & \\
\hline 18 & 0,633 & 2,109 & 85,929 & & & & & & \\
\hline 19 & 0,572 & 1,906 & 87,835 & & & & & & \\
\hline 20 & 0,536 & 1,785 & 89,620 & & & & & & \\
\hline 21 & 0,508 & 1,692 & 91,312 & & & & & & \\
\hline 22 & 0,442 & 1,473 & 92,785 & & & & & & \\
\hline 23 & 0,417 & 1,391 & 94,176 & & & & & & \\
\hline 24 & 0,404 & 1,345 & 95,521 & & & & & & \\
\hline 25 & 0,350 & 1,168 & 96,690 & & & & & & \\
\hline 26 & 0,315 & 1,051 & 97,741 & & & & & & \\
\hline 27 & 0,243 & 0,810 & 98,551 & & & & & & \\
\hline 28 & 0,196 & 0,652 & 99,203 & & & & & & \\
\hline 29 & 0,177 & 0,589 & 99,792 & & & & & & \\
\hline 30 & 0,062 & 0,208 & 100,00 & & & & & & \\
\hline
\end{tabular}

Método de extração: Análise dos componentes principais 
Tabela 2 - Comunalidades

\begin{tabular}{|c|c|c|}
\hline & Inicial & Extração \\
\hline ORDEM & 1,000 & ,669 \\
\hline IDADE & 1,000 &, 737 \\
\hline NATURAL & 1,000 &, 772 \\
\hline BAIRRO & 1,000 & ,718 \\
\hline SEXO & 1,000 &, 704 \\
\hline ENDEREÇO & 1,000 & ,653 \\
\hline GOIÂNIA & 1,000 & ,708 \\
\hline MIGROU & 1,000 & ,666 \\
\hline TERRAS & 1,000 & ,923 \\
\hline POSSUI & 1,000 &, 808 \\
\hline VENDA & 1,000 & ,675 \\
\hline EMPREGO & 1,000 & ,785 \\
\hline CIVIL & 1,000 & ,673 \\
\hline FILHOS & 1,000 &, 776 \\
\hline FAMÍLIA & 1,000 & ,641 \\
\hline TRABALHA & 1,000 &, 725 \\
\hline INFORMAL & 1,000 &, 762 \\
\hline ESCOLA & 1,000 & ,763 \\
\hline INSERIR & 1,000 &, 507 \\
\hline ANTERIOR & 1,000 & ,634 \\
\hline ÚNICA & 1,000 & ,670 \\
\hline TEMPO & 1,000 & ,685 \\
\hline SITUAÇÃO & 1,000 & ,481 \\
\hline PROCURA & 1,000 &, 515 \\
\hline MORADIA & 1,000 & ,628 \\
\hline RENDA & 1,000 & ,680 \\
\hline OUTRAS & 1,000 & ,609 \\
\hline INSS & 1,000 & ,675 \\
\hline CTPS & 1,000 & ,643 \\
\hline FORMAL & 1,000 & ,459 \\
\hline
\end{tabular}

Fonte: Dados da pesquisa observada está "carregada" em um fator (K erlinger, 1980). Dentro dessa concepção, quanto mais al ta a carga fatorial, mais a variável reflete e representa o fator.

A partir do resultado final de uma análise fatorial - a Matriz Fatorial Rotada -, pode-se tentar deduzir qual é a natureza dos onze fatores que conseguem explicar cerca de $67 \%$ da variabilidade dos dados. Sendo assim, pretende-se interpretar o significado de cada um dos fatores comuns.

Por meio do método Varimax, os fatores ficam mais estreitamente ligados a grupos específicos de variáveis, o que pode ser verificado na Tabela 3. Essa matriz mostra-nos as observações que apresentaram valores positivos e negativos para os fatores. As variáveis que apresentaram valores positivos e próximos de 1 são as mais identificadas com os fatores.

Dessa forma, ao analisar fatorialmente essa matriz de correlação, verifica-se que o fator 1 é formado pelas variáveis "migrou", "terras", "possui" e "emprego". Nota-se que essas variáveis estão positiva e substancialmente correlacionadas com o fator 1 . Como os fatores - originários da análise fatorial - possibilitam a análise dos dados agrupados, pode-se inferir que o fator 1 corresponde à migração da força de trabal ho do pequeno proprietário de terras do interior à cidade.

A natureza dessas variáveis - principalmente as variáveis "terras" e "possui", que estão mais fortemente correlacionadas com o fator 1 (apresentam coeficiente de correlação de 0,953 e de 0,861 , respectivamente) - indica que esse fator representa a posse de terras no interior.

Verifica-se que a variável "natural" estabelece uma correlação negativa com o fator 1 . Isto pode ser explicado porque 0 fator $1 \mathrm{diz}$ respeito aos trabalhadores que migraram do interior para Goiânia, enquanto a variável "natural" expressa a origem dos camelôs, das quais $70,4 \%$ não são naturais de $G$ oiânia.

A ssim, as variáveis que formam o fator 1 revelam que 33,57\% dos camelôs migraram para Goiânia em virtude do desemprego, apenas 9,9\% eram proprietários de terras no interior, somente $1 \%$ ainda possuem essas terras e $57,78 \%$ dos camelôs instalados em Goiânia e que são provenientes do interior não trabal havam, isto 
LEÃO, C.; LEITE, A. T. B. Caracterização das atividades informais...

Tabela 3 - Matriz Fatorial Rotada

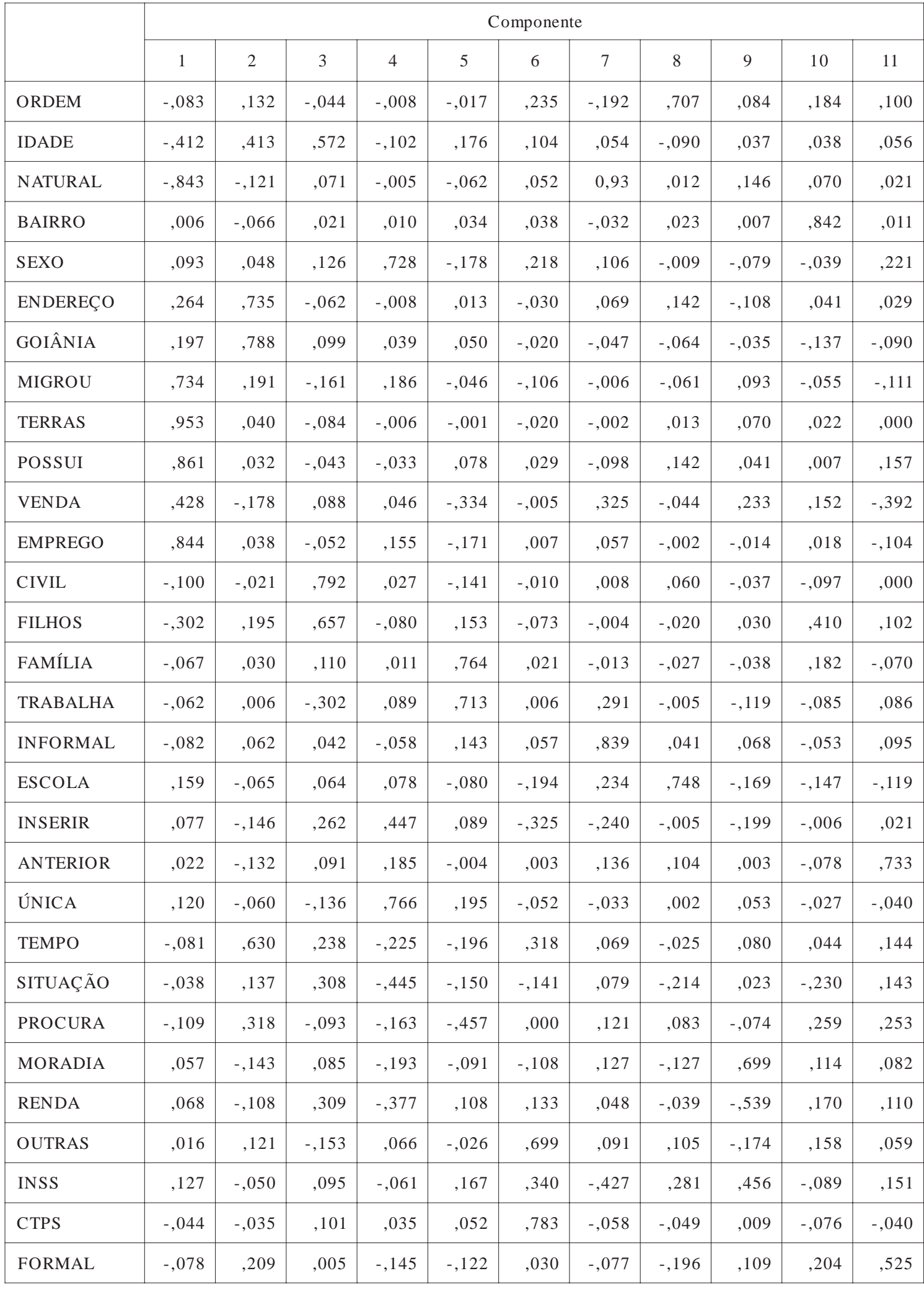

Método de extração: Análise dos componentes principais

Método de Rotação: Varimax

Fonte: Dados da pesquisa 
é, esses trabalhadores estavam desempregados no interior.

0 fator 2 agrupa as variáveis "endereço", "Goiânia" e "tempo", que denotam que esse fator remete ao tempo de exercício no comércio de rua de Goiânia.

A nalisando-se as cargas fatoriais relacionadas ao fator 3 , constata-se que esse fator está fortemente correlacionado com as variáveis "civil" e "filhos", o que significa que o fator 3 refere-se à composição familiar do camelô.

0 fator 4 está positiva e fortemente correlacionado com as variáveis "sexo" e "única", o que parece indicar que o homem é o principal responsável por exercer a atividade informal, que é a principal fonte de renda da família. Com isso, o fator 4 diz respeito ao homem se apresentar como o principal provedor do sustento dafamília.

0 fator 5 explica as variáveis "família" e "trabalha" e, assim, representa a relação da quantidade de pessoas/trabalho.

0 fator 6 mostra associação forte e positiva com as variáveis "outras" e "CTPS", o que parece indicar que esse fator diz respeito à segurança financeira do camelô. Nesse contexto, o fator 6 caracteriza a preocupação do camelô em garantir uma remuneração através de outras rendas além da recebida com a atividade informal, assim como ter uma carteira de trabal ho assinada, que lhe assegure al guns direitos trabal histas.

Entretanto, as variáveis que formam o fator 6 mostram que apenas 18,2 dos pesquisados declararam que têm outras rendas, assim como 98\% deles não têm registro atual na carteira de trabalho, o que os leva a um contexto de insegurança e vulnerabilidade

Já os fatores $7,8,9,10$ e 11 não se enquadram no critério estabelecido pela pesquisa de somente levar em consideração os coeficientes de correlação maiores do que 0,60. Dessa forma, al guns fatores somente abarcam uma variável que preenche esse requisito. A lém disso, a decisão de desconsiderar esses fatores tenta el iminar da anál ise os resul tados espúrios, que são as relações de causa e efeito estatisticamente correlatas, mas que, na realidade, são ilegítimas (A bramo, 1988).

\section{Conclusões}

Os principais fatores que caracterizam as atividades informais dos camelôs que atuam no centro de Goiânia, pela ordem de importância, são:

- migração da força de trabal ho do pequeno proprietário de terras do interior para Goiânia;

- tempo de exercício no comércio de rua do Centro de Goiânia;

- composição familiar do camelô;

- relação entre homem e principal fonte de renda;

- relação entre a quantidade de pessoas e o trabalho;

- segurança financeira do camelô.

Os camelôs que ocupam comercialmente as ruas goianienses são ex-desempregados provenientes de Goiânia ou do interior. Concluise que 0 desemprego esteve presente na determinação das variáveis que compõem 0 principal fator explicativo do fenômeno.

A busca de uma atividade por conta própria remete à única saída desses trabal hadores, que se encontravam desempregados porque não dispunham das condições de "empregabilidade" exigidas para o ingresso no mercado formal de trabalho.

Constata-se que os camelôs pesquisados são trabal hadores com baixa escolaridade, que apresentam uma idade avançada para os parâmetros de eficiência das empresas formais, além de terem em sua composição um grande número de mulheres (o mercado formal reserva para as mulheres o trabalho precário ou em tempo parcial, com uma remuneração reduzida).

Nesse contexto, as atividades informais, inicialmente concebidas como estratégia de sobrevivência para escapar do desemprego, transformam-se em uma ocupação que diz respeito à principal fonte de renda da família do camelô. Grande parcela da população pesquisada já se encontra na informalidade há mais de cinco anos e manifesta o interesse em continuar no exercício do comércio de rua, pois essa atividade não exige qualificação profissional, escolaridade, nem limite de idade, além de 
possibilitar ao camelô a organização do tempo dedicado ao trabalho.

A pesar disso, os trabalhadores autônomos estão excluídos do gozo dos direitos trabal histas, na medida em que não dispõem das vantagens trabal histas conferidas a quem se encontra empregado, como um salário fixo, férias remuneradas, $13^{\circ}$ salário, Fundo de Garantia por Tempo de Serviç̧o (FGTS) ou seguro-desemprego.

\footnotetext{
Abstract: This study aims to analyze the reasons of workers insertion in street commerce in downtown Goiânia. The questionnaires of the survey were applied to 203 informal workers who work in the center areas. The methodblogy included factor analysis that was carried out according to the method of principal components, and the SPSS program processed the data. The results showed the factors are: migration of unemployed workers from country to Goiânia; time of working in this activity, secure employment contracts that the informal workers have, among another factors. The conclusion is that the unemployment is the cause of informal work in downtown Goiânia.

Key-words: unemployment; factor analysis; informal work.
}

\section{Referências}

ABRAM O, Perseu. Pesquisa em ciências sociais. In: HIRA N O, Sedi (Org.). Pesquisa social - projeto e planejamento. São Paulo: T. A. Queiroz, Editor, 1988.

ANTUNES, Ricardo. Adeus ao trabalho? Ensaio sobre as metamorfoses e a centralidade do mundo do trabal ho. São Paulo: Cortez, 1995.
GU IM A RÃ ES, Nadya A raújo. Por uma sociologia do desemprego. Revista Brasileira de Ciências Sociais (on line), out. 2002, v. 17, n. 50, p. 104-121. Disponível no site: http://www.scielo.br. A cesso em: 4 jul. 2004.

HORTA , Carlos Roberto. Desemprego e cultura: uma leitura política da desconstrução da cidadania do trabalhador. In: HORTA, Carlos Roberto (Org.). Globalização, trabalho e desemprego: processos de inserção, desinserção e reinserção: enfoque internacional. B elo H orizonte: C/A rte, 2001.

KERLINGER, Fred N. M etodologia da pesquisa em ciências sociais: um tratamento conceitual. São Paulo: E.P.U./Edusp, 1980.

M EY ER, L eandro Frederico Ferraz; B RA GA, M arcelo José. Tipologia do uso agrícola do solo no estado do Pará: U ma aplicação de métodos de análise multivariada. Revista de Economia e Sociologia Rural, v. 39, n. 4, out./dez. 2001. Sociedade B rasileira de Economia e Sociologia Rural (Sober) - B rasília.

NORONHA, E duardo G. Informal, ilegal, injusto: percepções do mercado de trabal ho no B rasil. Revista Brasileira de Ciências Sociais, 2002. Disponível no site: http:// www.scielo.br.

SINGER, Paul. Globalização e desemprego diagnóstico e alternativas. 6. ed. São Paulo: Contexto, 2003.

SOUZA, Reginaldo Farias de; KHAN, A hmad Saeed. M odernização da agricultura e hierarquização dos municípios maranhenses. Revista de E conomia e Sociologia Rural, v. 39, n. 1, jan/mar., 2001. Sociedade B rasileira de Economia e Sociologia Rural (Sober) - Brasília.

YÁZIGI, Eduardo. 0 mundo das calçadas. São Paulo: H umanitas/FFL CH6/USP; Imprensa O ficial do Estado, 2000. 